\title{
PREPARATION OF DESULFURIZING ACTIVATED CARBON FROM CORN STALK AND CHARACTERIZATION OF DESULFURIZING STRUCTURE
}

\author{
Fen $\mathrm{LI}^{1}{ }^{*}, \mathrm{He} \mathrm{WANG}^{1}$, Yanping ZHANG ${ }^{2}$, Qifei WANG ${ }^{1}$ \\ ${ }^{1}$ College of Chemical and Environmental Engineering, Harbin University of Science \\ and Technology, Harbin 150000, Heilongjiang, China \\ ${ }^{2}$ School of Civil Engineering, Hebei University of Technology, Tianjin 300401, China
}

Received 01 August 2018; accepted 27 August 2018

\begin{abstract}
This study investigated the optimal conditions for preparing desulfurizing stalk carbon, using corn stalk as a raw material and zinc chloride as an activator. The structure of stalk carbon was characterized using thermogravimetry (TG), fourier transform infrared spectroscopy (FT-IR), scanning electron microscopy (SEM), X-ray photoelectron spectroscopy (XPS) and Brunauer - Emmelt - Teller (BET). Results found no significant difference in stalk carbon desulfurization properties when using stalk skin, core, or a skin-core mixture as raw material. The desulfurization performance of stalk carbon prepared using a skin-core mixture, was the most effective when the material : liquid ratio was 1:2; activation temperature was $350{ }^{\circ} \mathrm{C}$; and activation time was $70 \mathrm{~min}$. The corresponding $\mathrm{H}_{2} \mathrm{~S}$ adsorption time was $74 \mathrm{~min}$. The large specific surface area of $562.28 \mathrm{~m}^{2} / \mathrm{g}$ and abundant pore-volume of $0.3851 \mathrm{ml} / \mathrm{g}$ was found in the desulfurization stalk carbon prepared using these conditions. The increase in micropores and the abundant oxygen-containing functional surface groups were conducive to $\mathrm{H}_{2} \mathrm{~S}$ adsorption. The desulfurization products were found to be mainly elemental $\mathrm{S}$ and sulfite.
\end{abstract}

Keywords: corn stalk, activated carbon, deodorization, adsorption, biomass, hydrogen sulfide.

\section{Introduction}

$\mathrm{H}_{2} \mathrm{~S}$ is a common air pollutant generated by petrochemical plants, gas plants, sewage treatment plants, paper mills, and other industries (Latos, Karageorgos, Kalogerakis, \& Lazaridis, 2011; Bouchy, 2011). $\mathrm{H}_{2} \mathrm{~S}$ is highly toxic and exposure to low doses can damage the central nervous systems of living organisms. It can also harm the environment and corrode buildings and steel as acid rain (Burgess, Parsons, \& Stuetz, 2001; E. Y. Lee, N. Y. Lee, Cho, \& Ryu, 2006). Therefore, it is necessary to treat waste gas to avoid $\mathrm{H}_{2} \mathrm{~S}$ emissions. Activated carbon adsorbents are widely used, especially using modified carbon. Some researchers have also used alkali modified activated carbon; metal ion can also be used (Shang, Li, Liu, Chen, \& Huang, 2016; Zhang, Cui, Chen, Dong, \& Tang, 2018; Danh, Teresa, \& Bandosz, 2005). In recent years, researchers have assessed the ability of many novel carbon materials to absorb malodorous gases. For example, applied modified carbon nanotubes have been used to test the adsorption of $\mathrm{H}_{2} \mathrm{~S}$ (Ali, Jafar, Alimorad, Mohajeri, \& Mohamadmehdi, 2011). Chen discussed the properties of $\mathrm{H}_{2} \mathrm{~S}$-adsorbing activated carbon fiber (Chen et al., 2010), and Omar used modified graphene to core), this study may help reduce environmental pollution caused by malodorous gas and stalk waste disposal, and help operators achieve sustainable waste treatment.

\section{Experimental details}

\subsection{Preparation of corn stalk carbon}

The skin and core of corn stalks were stripped and crushed through a 40 -mesh sieve. A $3 \mathrm{~mol} / \mathrm{L} \mathrm{ZnCl}_{2}$ carbon activator solution was prepared and the corn stalk material was dipped into the $\mathrm{ZnCl}_{2}$ solution at different corn stalk/ $\mathrm{ZnCl}_{2}$ material liquid ratios $(\mathrm{m} / \mathrm{V})$ for $24 \mathrm{~h}$. Corn stalk material was then dried in an oven and placed in an $\mathrm{N}_{2}$ atmosphere muffle furnace for 50-90 min with an activation temperature of $300-600{ }^{\circ} \mathrm{C}$. The product was cooled to ambient temperature and particles were washed with water to remove $\mathrm{ZnCl}_{2}$ from the material. The material was then dried at $85{ }^{\circ} \mathrm{C}$ for between 0.5 to $0.8 \mathrm{~h}$, to obtain corn stalk activated carbon (AC). The mass of carbon materials prepared from each preparation batch, was approximately $2.0 \mathrm{~g}$. AC can be formed from different tissue

${ }^{*}$ Corresponding author. E-mail: hgxylf@126.com 
types of maize stalk, including stalk core (ACc), stalk skin (ACs), and from stalk skin-core mixtures (ACm). Samples prepared under different process conditions are denoted by the system: ACRxTytz. In this expression, the material liquid ratio is $\mathrm{Rx}(\mathrm{R} 0, \mathrm{R} 1, \mathrm{R} 2, \mathrm{R} 3, \mathrm{R} 4)$, which refer to material liquid ratios of 1:0, 1:1, 1:2, 1:3, 1:4, respectively. The activation temperature was $\mathrm{Ty}$; and the activation time was tz.

\subsection{Adsorption performance test of $\mathrm{H}_{2} \mathrm{~S}$}

Gas chromatography GC-9160 (China, Ouhua) was used to measure the $\mathrm{H}_{2} \mathrm{~S}$ concentration, with the adsorption time of $\mathrm{H}_{2} \mathrm{~S}$ used as an index to measure the desulfurization performance of stalk carbon. A sample of $0.2 \mathrm{~g}$ stalk carbon was placed in a long glass tube reactor $(450 \mathrm{~mm}$ length and a $9 \mathrm{~mm}$ inner diameter). $\mathrm{H}_{2} \mathrm{~S}$ (1005.2 ppm) was added to the reactor at room temperature, at a speed of $20 \mathrm{ml} / \mathrm{min}$, with the $\mathrm{H}_{2} \mathrm{~S}$ concentration measured in effluent at 5 min intervals. The time at which the $\mathrm{H}_{2} \mathrm{~S}$ was detected in the gas chromatograph above the trace concentration $(>20 \mathrm{ppm})$ was recorded. Following this, the $\mathrm{H}_{2} \mathrm{~S}$ concentration was measured using the gas chromatogram every 2 minutes.

a)

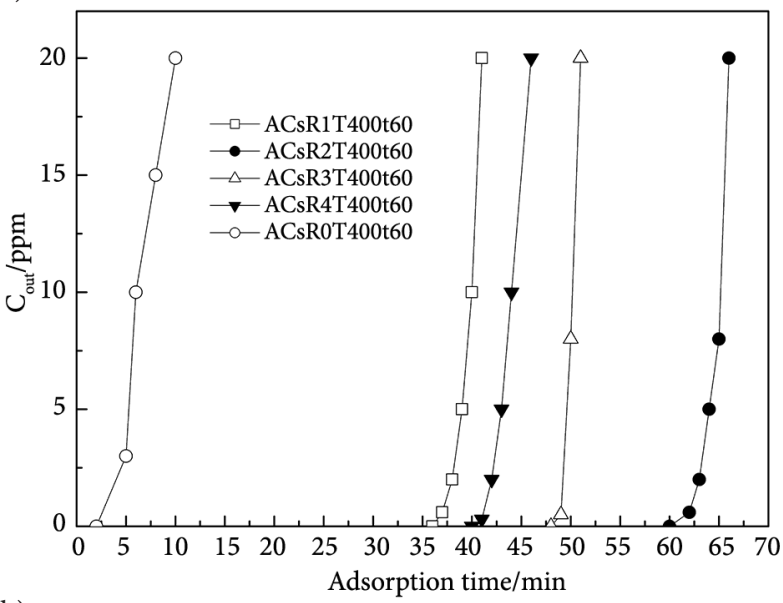

b)

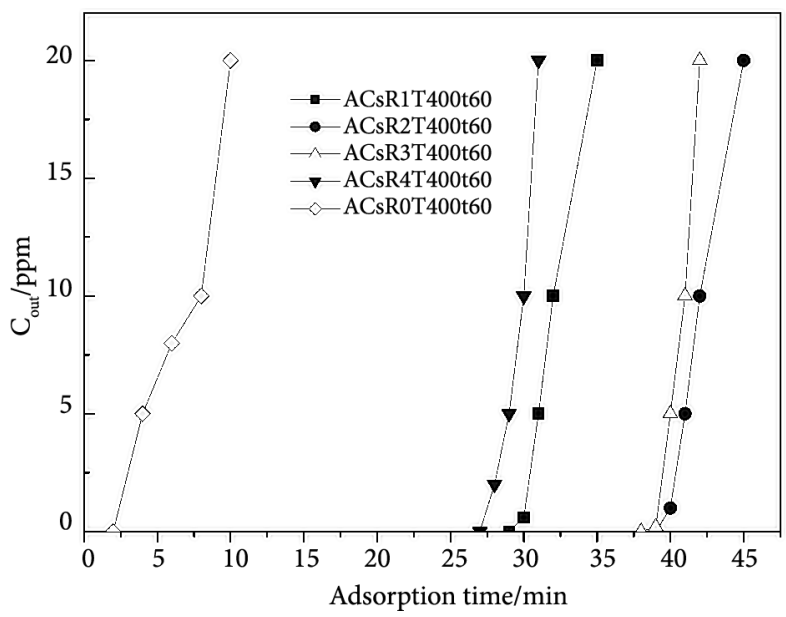

Figure 1. Adsorption time curves for stalk carbon prepared using different material liquid ratios (a: ACs; b: ACc)

\subsection{Analytical methods}

Thermogravimetric analysis of samples was performed using a STA449C thermogravimetric analyzer (Germany Netzsch, with a $\mathrm{N}_{2}$ atmosphere, and a heating rate of $10{ }^{\circ} \mathrm{C} / \mathrm{min}$, and a final temperature of $\left.1000{ }^{\circ} \mathrm{C}\right)$. X-ray photoelectron spectroscopy (XPS) was performed using a PHI5700ESCA spectrometer (America, PHI), with an Al $\mathrm{Ka}(\mathrm{hv}=1486.6 \mathrm{eV}) \mathrm{X}$-ray source, a target voltage of 13 $\mathrm{kV}$, and target power of $300 \mathrm{~W}$. Scanning electron microscopy (SEM) was performed using an FEI's Quanta 200. Infrared spectroscopy (FT-IR) was performed using a T60SXBFTIR infrared spectrometer (America, NICOLE). The specific surface area and pore structure were measured using a ASAP2020 (America, Micromeritic) surface area and pore analyzer. The specific surface areas of samples were calculated using the Brunauer - Emmelt - Teller (BET) surface area (Titus \& Martens, 2011) method, and the pore volume and pore size distribution were calculated using the Barret - Johner - Halenda (BJH) analysis method (Majid Hayati-Ashtiani, 2012).

\section{Results and discussion}

\subsection{Effect of material liquid ratio on stalk carbon desulfurization performance}

The effects of different material liquid ratios (corn stalk/ $\mathrm{ZnCl}_{2}$ ) on the desulfurization performance of stalk carbon are shown in Figure 1 (a: ACs; b: ACc). Figure 1a and Figure $1 \mathrm{~b}$ show that stalk carbon without activation (material to liquid was 1:0) had the lowest desulfurization effects. Stalk carbon had the best desulfurization effect when the ratio of material to liquid was 1:2 (both ACsR2T400t60 and ACcR2T400t60) and an $\mathrm{H}_{2} \mathrm{~S}$ adsorption time of up to $60 \mathrm{~min}$. The desulfurization performance of the stalk skin carbon material was slightly better than the stalk core. A specific optimal volume of $\mathrm{ZnCl}_{2}$ is needed when preparing carbon materials. This because when there is limited activator volume, the pore structure is not developed. This reduces the adsorption performance of the material (Church, Jasso, Björnerbäck, \& Niklas, 2017). However, when too much activator is applied, there is excessive activation and pore structure damage. This also affects the adsorption activity of stalk carbon. From a cost-benefit perspective, a low material liquid ratio is optimal, therefore the material liquid ratio was selected to be 1:2.

\subsection{Effect of activation temperature on desulfurization performance of stalk carbon}

The $\mathrm{H}_{2} \mathrm{~S}$ adsorption time curves for stalk carbon prepared using different activation temperatures are shown in Figure 2 (a: ACs; b: ACc). When the activation temperature increased, the $\mathrm{H}_{2} \mathrm{~S}$ adsorption properties of stalk carbon prepared from skin and core showed a similar pattern (Figure 2). Figure 2a and Figure $2 \mathrm{~b}$ indicate that an excessively high or low activation temperature is not conducive to effective $\mathrm{H}_{2} \mathrm{~S}$ adsorption. When the activation 

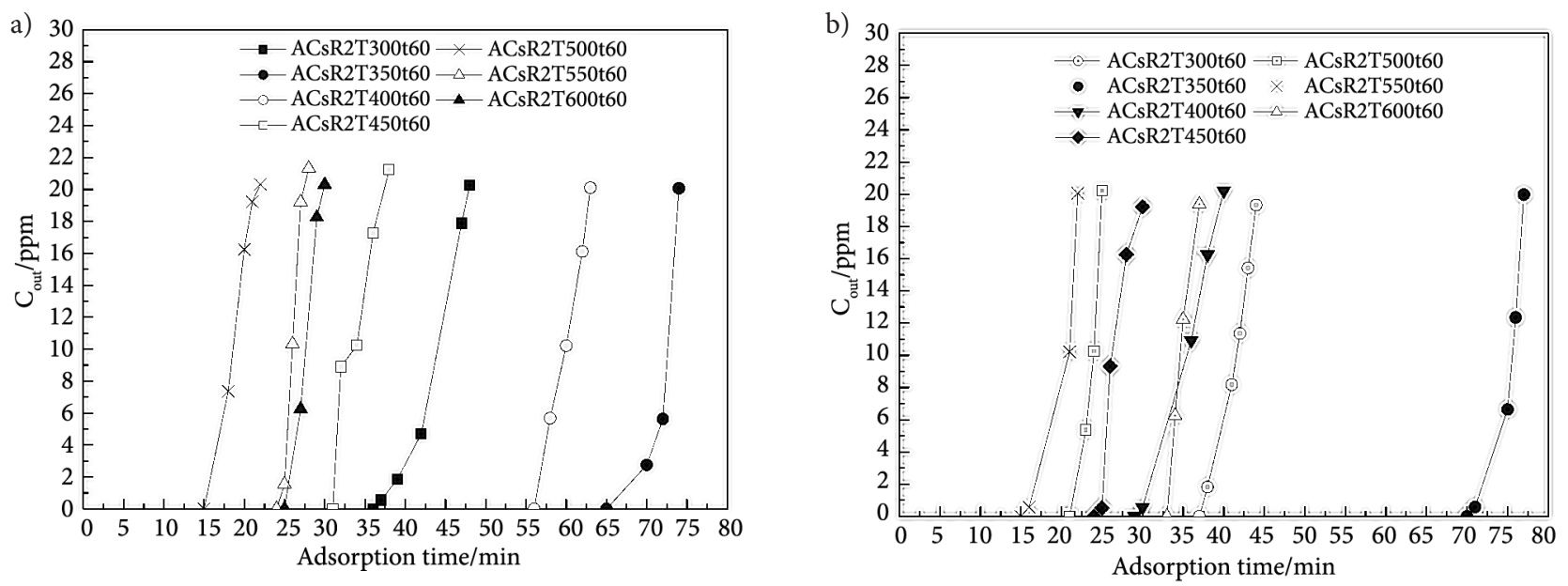

Figure 2. Adsorption time curves for stalk carbon prepared using different activation temperatures (a: ACs; b: ACc)

temperature is low, the stalk organic matter is not fully carbonized and too few micropores are formed. This results in inadequate adsorption effects. When the activation temperature is very high, organic matter in the stalk evaporates easily, destroying the original pore structure and increasing the number of meso-pores and macropores. This significantly reduces the specific surface area ( $\mathrm{Li}, \mathrm{Gu}, \&$ Zhao, 2010). These results show that when the activation temperature was $350{ }^{\circ} \mathrm{C}$, the stalk carbon had the optimal desulfurization performance (ACsR2T350t60 and ACcR2T350t60), with no significant difference observed between the skin and core. The adsorption time for $\mathrm{H}_{2} \mathrm{~S}$ reached 70 min.

\subsection{Effect of activation time on desulfurization performance of stalk carbon}

$\mathrm{H}_{2} \mathrm{~S}$ adsorption time curves for stalk carbon prepared with different activation times are shown in Figure 3 (a: ACs; $\mathrm{b}$ : ACc). There was no significant difference observed in the desulfurization performance of stalk carbon prepared from skin or core (Figure 3). As activation time increased,

a)

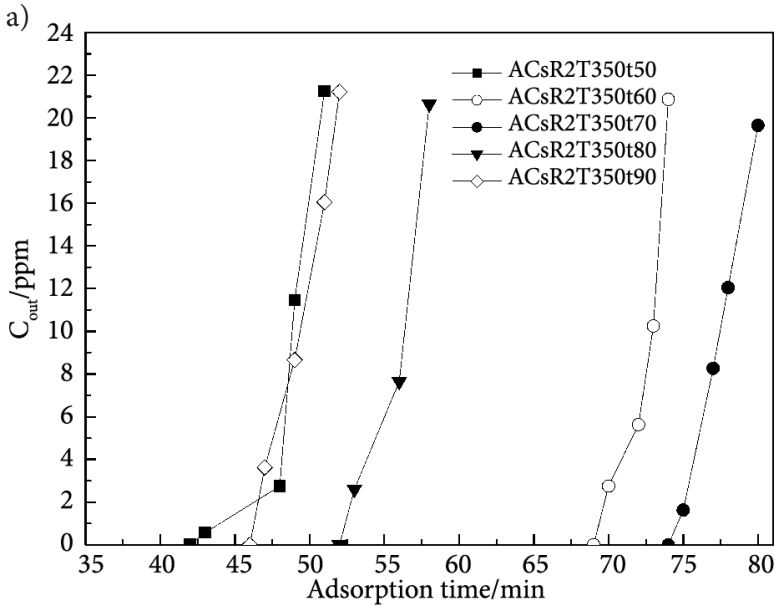

the desulfurization performance of the two kinds of stalk carbon both initially increased, followed by decreasing desulfurization efficiency. When the activation time was 70 min (ACsR2T350t70 and ACcR2T350t70), the $\mathrm{H}_{2} \mathrm{~S}$ adsorption time achieved an optimal performance of $74 \mathrm{~min}$. With an excessively long activation time, it may lead to sintering of part of the pore structure, reducing both the specific surface area and the adsorption capacity of stalk carbon. However, if the activation time is too short, the stalk activation will be incomplete, also reducing adsorption effects. Therefore, $70 \mathrm{~min}$ is the optimal activation time for stalk carbon.

In summary, the optimal $\mathrm{H}_{2} \mathrm{~S}$ adsorption effects of carbon materials prepared from stalk skin and core were observed with a material liquid ratio of $1: 2$, an activation temperature of $350{ }^{\circ} \mathrm{C}$, and an activation time of $70 \mathrm{~min}$. Figure 4 shows that the $\mathrm{H}_{2} \mathrm{~S}$ adsorption time for stalk carbon prepared from the skin-core mixture was approximately 74 min (ACmR2T350t70), with no significant difference observed in stalk carbon prepared using the three different raw materials.

b)

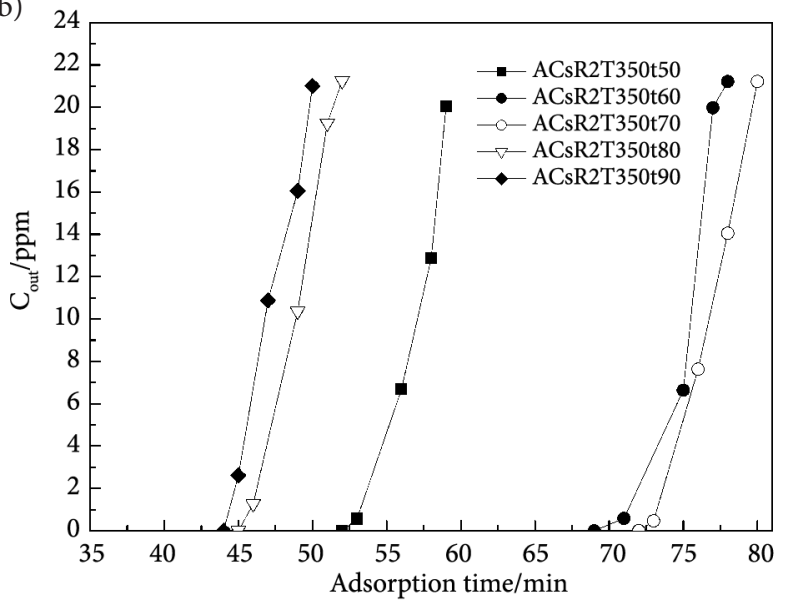

Figure 3. Adsorption time curves of different activation time (a: ACs; b: ACc) 


\subsection{Analysis of surface functional groups of stalk carbon}

Figure 5 shows the thermogravimetric curves (TG) for corn stalk raw material (a) and corn stalk raw material impregnated with $\mathrm{ZnCl}_{2}$ at a material liquid ratio of $1: 2$ (b). Figure 6 shows the FT-IR curves for corn stalks prepared under different conditions. The TG curves (Figure 5) show that the physico-chemical changes that occur in corn stalk during pyrolysis can be divided into three stages. The first stage is mainly water evaporation, where the temperature is between ambient temperature and $105{ }^{\circ} \mathrm{C}$. The weight loss of corn stalk (Figure 5a) was lower than the loss observed in corn stalk impregnated with the $\mathrm{ZnCl}_{2}$ activator (Figure 5b). This is because the $\mathrm{ZnCl}_{2}$ agent is highly deliquescent, absorbing moisture from the environment and resulting in an increased weight loss ratio.

In the second stage, the temperature range was between $105-400{ }^{\circ} \mathrm{C}$. Figure $5 \mathrm{~b}$ shows that the weight loss ratio is lower in the activated stalk carbon than in the stalk carbon alone (Figure 5a). This indicates that adding a $\mathrm{ZnCl}_{2}$ activator inhibits the volatilization of carbon materials, complicating the pyrolysis process. This stage is the medium temperature solution phase, where the chemical bonds of cellulose, hemicellulose and lignin are broken and rearranged. This resulted in the production of many volatile substances and high boiling point products. In this stage, solid carbon is generated along with $\mathrm{CO}_{2}, \mathrm{H}_{2} \mathrm{O}$, and $\mathrm{CO}$. At this temperature range (Figure 6c ACmR2T350t70; Figure $6 \mathrm{~d}$ ACmR2T400t70), the main remaining oxygen functional groups are carbonyl at 1614 and $1604 \mathrm{~cm}^{-1}$, ether groups at 1114 and $1136 \mathrm{~cm}^{-1}$ (Soares, Camino, \& Levchik, 1995; Zeng, Zhou, \& Ai, 2013).

In the third stage, cellulose pyrolysis occurs at the high temperature range of between $400-600{ }^{\circ} \mathrm{C}$. The residual structure of cellulose undergoes aromatic cyclization, which mainly produces polycyclic aromatic hydrocarbons (D. Y. Choi, Lee, Jang, Ahn, \& D. K. Choi, 2008). In this temperature range (Figure 6e ACmR2T500t70; Figure $6 \mathrm{f}$ ACmR2T600t70), the remaining oxygen-containing functional groups were still mainly ether $\left(1185,1114 \mathrm{~cm}^{-1}\right)$ and carbonyl $\left(1606,1601 \mathrm{~cm}^{-1}\right)$ groups. This indicates that the groups that formed when the stalk was pyrolyzed at $200-400{ }^{\circ} \mathrm{C}$ persisted, and that new functional groups were not formed by increasing the pyrolysis temperature (Mcgrath, Chan, \& Hajaligol, 2003). This conclusion is consistent with the findings on carbonization and activation of cellulose, as well as research on bamboo charcoal and rice husk charcoal (Shang et al., 2016; El-Hendawy, 2006).

Figure 6 shows that the wavenumber of all 6 samples showed an absorption peak at $3420-3434 \mathrm{~cm}^{-1}$, which can be attributed to the stretching vibration peak of hydroxyl groups $(\mathrm{OH})$. The wave number absorption peak at $1601-1644 \mathrm{~cm}^{-1}$ can be attributed to the carbonyl $(\mathrm{C}=$ O) absorption peak. The peak intensity (Figure $6 \mathrm{~b} \mathrm{ACm}-$ R0T350t70 and Figure 6c ACmR2T350t70) in activated corn stalk was stronger than the peak intensity of corn

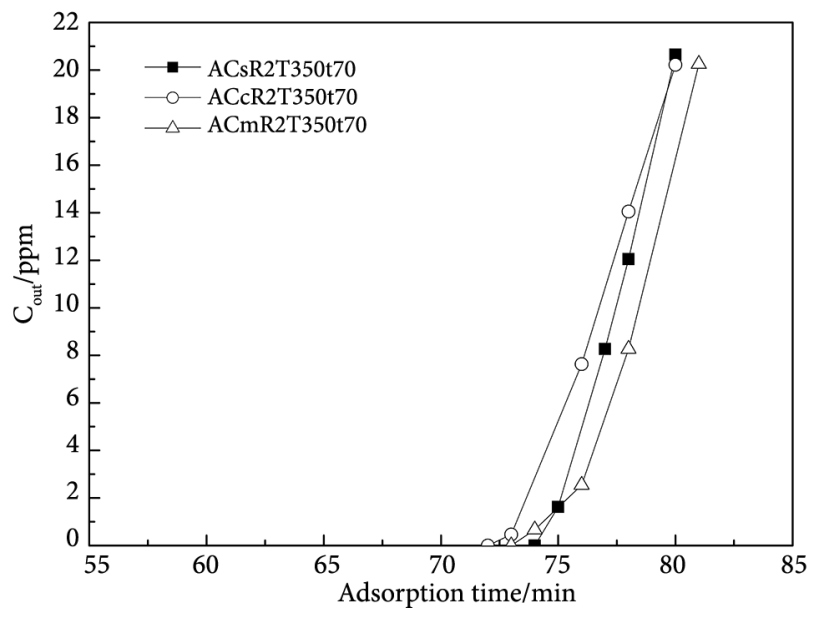

Figure 4. Adsorption time curves for different stalk carbon raw materials

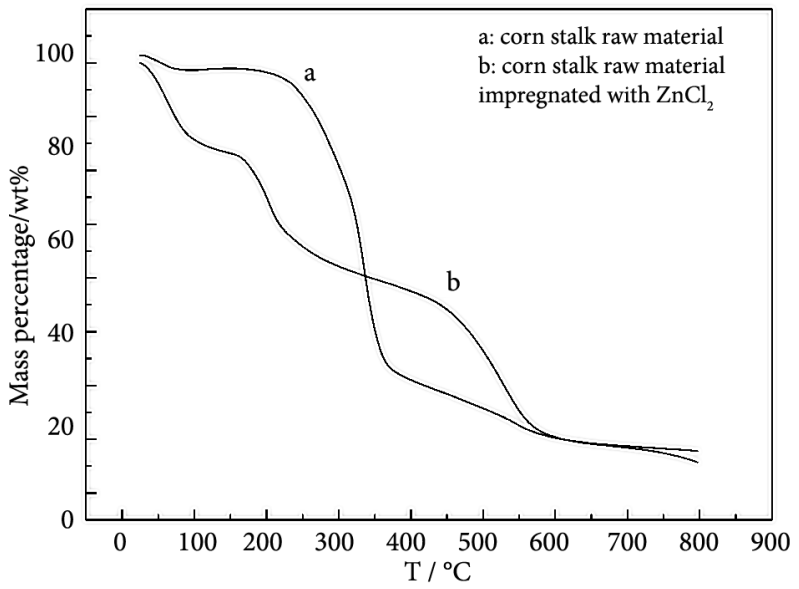

Figure 5. Thermogravimetric analysis curves of corn stalk raw material

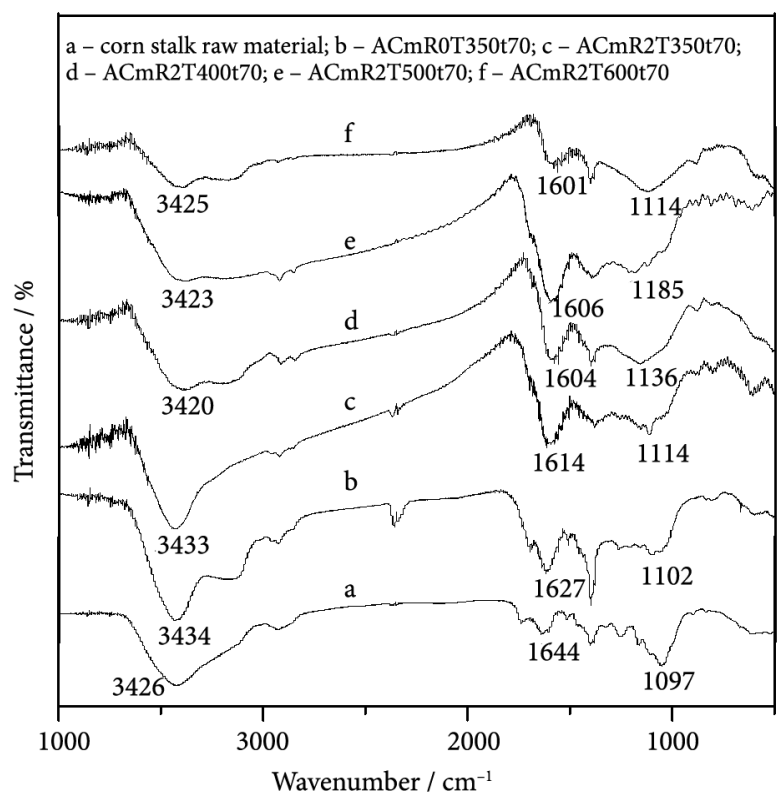

Figure 6. FT-IR curves of materials produced under different conditions 
stalk (Figure 6a corn stalk raw material). These datas show that the roasting process can significantly increase the number of oxygen - containing functional groups on the surface of stalk carbon, with the absorption peak at $1097-1185 \mathrm{~cm}^{-1}$ being attributed to the C-O-C structure. Comparing the datas presented in Figure $6 \mathrm{~b}$ and Figure $6 c-6 \mathrm{f}$ show that adding an activator has no significant effect on the type of functional groups formed on the surface of the stalk carbon. These findings were consistent with past research (Li et al., 2016).

\subsection{Analysis of surface morphology and pore structure of stalk carbon}

Figure 7 shows a scanning electron micrograph (SEM) of carbon material. This figure shows that the prepared carbon materials have pipe-shaped channels. Channel walls are porous (Figure $7 \mathrm{a}, \mathrm{b}, \mathrm{c}$ the pores in the channel walls are marked with circles), no significant difference was observed in the structure of these three materials. In the case of ACmR0T350t70 produced without activation (Figure $7 \mathrm{~d}$ ) pipe-shaped channels have been formed, but channel walls are not porous. Therefore, this material shows relatively poor $\mathrm{H}_{2} \mathrm{~S}$ adsorption effect. By comparing the pore structure of materials produced by the use of activation and without using it, it shows that activation contribute to the pore structure development (Tsai, Chang, \& Lee, 1998; Mohanty, Das, \& Biswas, 2006).

The pore structure and specific surface area of stalk carbon samples were measured to analyze the pore structure of the materials, as shown in Table 1 and Figure 8. Table 1 shows that the specific surface area of carbonized material without activation by $\mathrm{ZnCl}_{2}$ (ACmR0T350t70) was only $47.63 \mathrm{~m}^{2} / \mathrm{g}$, with an average pore diameter of $5.99 \mathrm{~nm}$. The large pore volume is due to contributions by mesopores and macropores with diameters exceeding $2 \mathrm{~nm}$. However, the specific surface area of stalk carbon prepared with the addition of $\mathrm{ZnCl}_{2}$ (ACmR2T350t70) increased to $562.28 \mathrm{~m}^{2} / \mathrm{g}$, with an average pore size of $2.95 \mathrm{~nm}$. In activated samples, the pore volume was $0.3851 \mathrm{ml} / \mathrm{g}$ higher due to a larger contribution by $\mathrm{mi}$ cropores, with pore size volumes below $2 \mathrm{~nm}$ account for $0.2044 \mathrm{ml} / \mathrm{g}$. This indicates that the stalk activation processes are conducive to micropore formation. The specific surface area of stalk carbon after $\mathrm{H}_{2} \mathrm{~S}$ adsorption decreased significantly, with no micropores detection. This indicates that adsorption reactions are mainly performed in micropores with a pore size smaller than $2 \mathrm{~nm} . \mathrm{H}_{2} \mathrm{~S}$

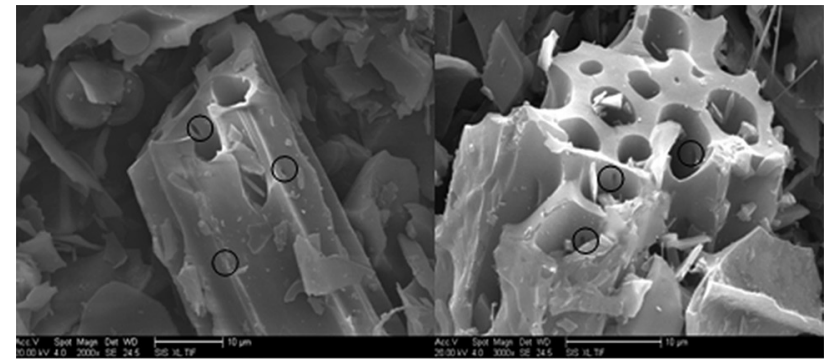

a)

b)

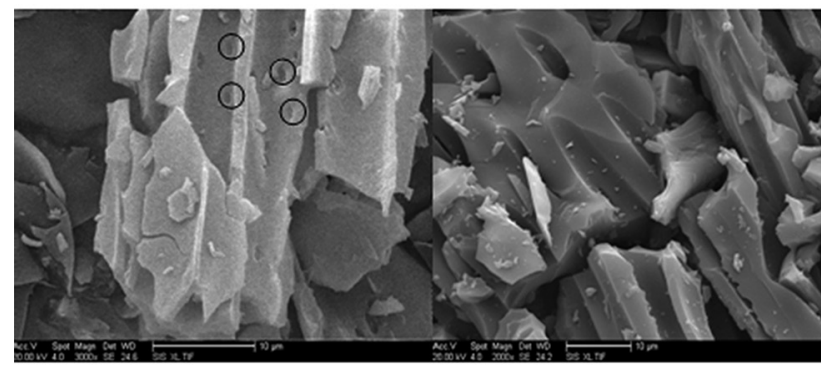

c)

d)

Figure 7. SEM pictures of different stalk carbon samples (a: ACsR2T350t70; b: ACcR2T350t70; c: ACmR2T350t70; d: ACmR0T350t70)

was oxidized until all effective pores of the catalysts were blocked by the oxidation products.

Figure 8 shows the $\mathrm{N}_{2}$ adsorption and desorption isotherms before and after $\mathrm{H}_{2} \mathrm{~S}$ adsorption on stalk carbon (ACmR2T350t70). Figure 8a shows the adsorption isotherm of ACmR2T350t70. According to the IUPAC adsorption isotherm, the adsorption desorption isotherm of stalk carbon accords with a type I sorption isotherm. When the $\mathrm{P} / \mathrm{P}_{0}$ is in the low-pressure region, the sample begins to absorb a large amount of $\mathrm{N}_{2}$, indicating that the internal structure of stalk carbon is mainly microporous. Figure $8 \mathrm{~b}$ is the adsorption isotherm of ACmR2T350t70 after $\mathrm{H}_{2} \mathrm{~S}$ adsorption. The adsorption desorption isotherm of stalk carbon is consistent with a type III sorption isotherm. The key characteristic is the weak interaction between the solid surface and the adsorbed molecules. Figure $8 \mathrm{~b}$ shows that there is no adsorption in the low - pressure section, which shows there was no micropore. In summary, micropores play the major role in the adsorption process. This is consistent with the research results of Chen; that study found that pores with size larger than $0.7 \mathrm{~nm}$ is conducive to $\mathrm{H}_{2} \mathrm{~S}$ adsorption (Chen et al., 2010).

Table 1. The pore structure and BET of activated carbon samples before and after $\mathrm{H}_{2} \mathrm{~S}$ adsorption

\begin{tabular}{|l|c|c|c|c|}
\hline \multicolumn{1}{|c|}{ Sample } & $\begin{array}{c}\mathrm{BET} \\
/\left(\mathrm{m}^{2} / \mathrm{g}\right)\end{array}$ & $\begin{array}{c}\text { Average pore } \\
\text { size } / \mathrm{nm}\end{array}$ & $\begin{array}{c}\text { Pore volume }(>2 \mathrm{~nm}) \\
/(\mathrm{ml} / \mathrm{g})\end{array}$ & $\begin{array}{c}\text { Pore volume }(<2 \mathrm{~nm}) \\
/(\mathrm{ml} / \mathrm{g})\end{array}$ \\
\hline ACmR0T350t70 & 47.63 & 5.99 & 0.0877 & 0 \\
\hline ACmR2T350t70 & 562.28 & 2.95 & 0.1807 & 0.2044 \\
\hline $\begin{array}{l}\text { ACmR2T350t70 after } \\
\mathrm{H}_{2} \text { S adsorption }\end{array}$ & 42.24 & 9.02 & 0.1111 & 0 \\
\hline
\end{tabular}



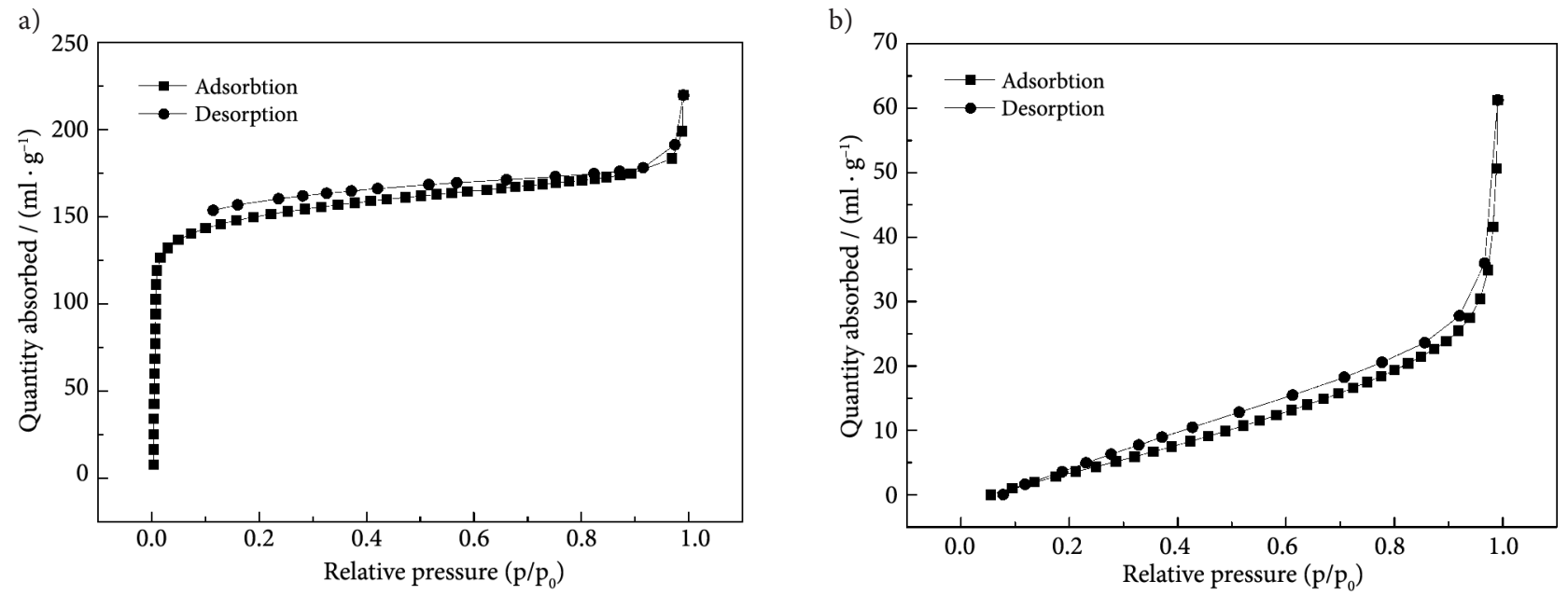

Figure 8. $\mathrm{N}_{2}$ Absorption and desorption isotherm of activated carbon (a: ACmR2T350t70; b: ACmR2T350t70 after $\mathrm{H}_{2} \mathrm{~S}$ adsorption)

\subsection{Analysis of products after $\mathrm{H}_{2} \mathrm{~S}$ adsorption}

To establish the valence state of $\mathrm{S}, \mathrm{X}$-ray photoelectron spectroscopy was used to analyze sample ACmR2T350t70

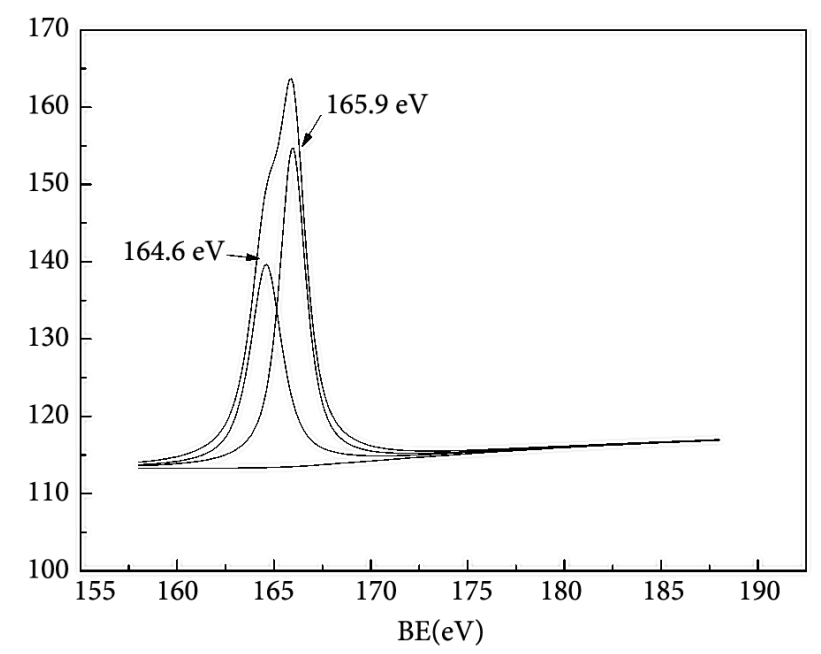

Figure 9. $\mathrm{S}_{2} \mathrm{P}$ XPS spectrogram ACmR2T350t70 after adsorption of $\mathrm{H}_{2} \mathrm{~S}$

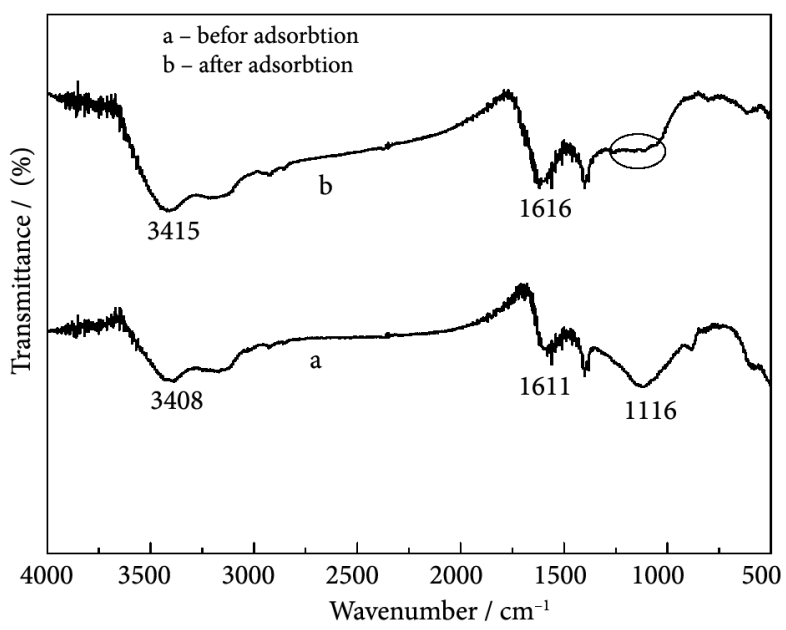

Figure 10. FT-IR curves before and after adsorption of $\mathrm{H}_{2} \mathrm{~S}$ (ACmR2T350t70) after $\mathrm{H}_{2} \mathrm{~S}$ adsorption. Figure 9 shows the XPS fit of $\mathrm{S}_{2 \mathrm{p}}$, and shows two distinct peaks. The electron binding energy peak at $164.6 \mathrm{eV}$ belongs to elemental S, while the electron binding energy at $165.9 \mathrm{eV}$ belongs to $S$ in sulfite. This indicates that $\mathrm{H}_{2} \mathrm{~S}$ was oxidized to elemental $\mathrm{S}$, which was then oxidized to $\mathrm{SO}_{2}$, which could react with water to form sulfite. The dissolution and adsorption mechanisms of activated carbon can explain the process of desulfurization (Klein \& Henning, 1984). Stalk carbon adsorbs water in the gas to form a layer of water film. At the same time, $\mathrm{H}_{2} \mathrm{~S}$ and oxygen enter the activated carbon pore by diffusion and $\mathrm{HS}^{-}$and active oxygen atoms are generated by ionization in the water film (Xie, Yi, Hu, Zheng, \& Chen, 2011). Finally, active oxygen atoms react with $\mathrm{HS}^{-}$to generate $S$ and are deposited in the pores of activated carbon, as illustrated in equation (1):

$$
\mathrm{H}_{2} \mathrm{~S}+1 / 2 \mathrm{O}_{2} \rightarrow \mathrm{S}+\mathrm{H}_{2} \mathrm{O} \text {. }
$$

Areas containing many oxygen containing functional groups are considered to be the catalytic center of activity. Studies have shown that increasing the concentration of carbonyl and ether functional groups on the surface of activated carbon can greatly improve the desulfurization capability of activated carbon (Wu, Huang, \& Zhang, 2009). Figure 10 presents the FT-IR curves for ACmR2T350t70 and ACmR2T350t70 after $\mathrm{H}_{2} \mathrm{~S}$ adsorption. The ACmR2T350t70 (Figure 10a) spectra contains a significant peak at $1116 \mathrm{~cm}^{-1}(\mathrm{C}-\mathrm{O}-\mathrm{C})$, while the spectra for ACmR2T350t70 after $\mathrm{H}_{2} \mathrm{~S}$ adsorption (Figure 10b) the peak became invisible. This indicates that the $\mathrm{C}-\mathrm{O}-\mathrm{C}$ bond is the main reactive group involved in desulfurization.

\section{Conclusions}

Corn stalk skin, core, and skin-core mixture were compared as raw materials. $\mathrm{ZnCl}_{2}$ was used as the activator to prepare the activated stalk carbon. Results show there were no significant differences in the capacity of carbon materials to adsorb $\mathrm{H}_{2} \mathrm{~S}$ prepared from different parts of 
the stalk. When the activation temperature was $350{ }^{\circ} \mathrm{C}$, the ratio of material to liquid was $1: 2$ and the activation time was $70 \mathrm{~min}$. In contrast, when mixed material was used, the time required for $\mathrm{H}_{2} \mathrm{~S}$ to adsorb to the stalk carbon was $74 \mathrm{~min}$.

Structural analysis showed that oxygen containing functional groups on the surface of stalk carbon increased after calcination. There was no significant change in the composition of functional groups on the surface of the activated carbon after adding the activator. However, many pores formed on the surface of stalk carbon; the contribution of micropores to the total pore system reached $53.1 \%$, indicating that micropores may be the main sites for $\mathrm{H}_{2} \mathrm{~S}$ adsorption.

The results of XPS showed that $\mathrm{H}_{2} \mathrm{~S}$ existed mainly in the form of elemental S and sulfite, which was consistent with known dissolution and adsorption mechanisms for activated carbon. In addition, the presence of oxygencontaining functional groups of $(\mathrm{C}-\mathrm{O}-\mathrm{C})$ on the surface of stalk carbon was also found to play a major role in the catalytic oxidation of $\mathrm{H}_{2} \mathrm{~S}$.

Stalk carbon adsorbs $\mathrm{H}_{2} \mathrm{~S}$ and converts it into elemental $\mathrm{S}$ and sulfite. Based on the effects from $\mathrm{H}_{2} \mathrm{~S}$ adsorption and removal, we found that the chemical adsorption reaction dominated the process.

\section{Acknowledgements}

This research was supported by the National Natural Science Foundation of China (No. 51608166). The authors also acknowledge the Support of Technological innovation for special funds of Harbin (No. 2014RFQXJ056).

\section{References}

Ali, M., Jafar, T., Alimorad, R., Mohajeri, A., \& Mohamadmehdi, G. (2011). Modification of carbon nanotubes for $\mathrm{H}_{2} \mathrm{~S}$ sorption. Industrial \& Engineering Chemistry Research, 50(13), 8050-8057. https://doi.org/10.1021/ie102583r

Azargohar, R., \& Dalai, A. K. (2011). The direct oxidation of hydrogen sulphide over activated carbons prepared from lignite coal and biochar. Canadian Journal of Chemical Engineering, 89(4), 844-853. https://doi.org/10.1002/cjce.20430

Bouchy, L. (2011). Odor assessment and management in wastewater treatment plants: a review. Critical Reviews in Environmental Science \& Technology, 41(10), 915-950. https://doi.org/10.1080/10643380903300000

Burgess, J. E., Parsons, S. A., \& Stuetz, R. M. (2001). Developments in odour control and waste gas treatment biotechnology: a review. Biotechnology Advances, 19(1), 35-63. https://doi.org/10.1016/S0734-9750(00)00058-6

Chen, Q., Wang, Z., Long, D. H., Liu, X. J., Zhan, L., Xiao, L., Qiao, W. M., \& Ling, L. C. (2010). Role of pore structure of activated carbon fibers in the catalytic oxidation of $\mathrm{H}_{2} \mathrm{~S}$. Industrial \& Engineering Chemistry Research, 49(7), 3152-3159. https://doi.org/10.1021/ie901223j

Choi, D. Y., Lee, J. W., Jang, S. C., Ahn, B. S., \& Choi, D. K. (2008). Adsorption dynamics of hydrogen sulfide in impregnated activated carbon bed. Adsorption-Journal of the International Adsorption Society, 14(4-5), 533-538.

https://doi.org/10.1007/s10450-008-9118-9
Church, T. L., Jasso, A. B., Björnerbäck, F., \& Niklas, H. (2017). Sustainability of microporous polymers and their applications. Science China Chemistry, 60(8), 1033-1055. https://doi.org/10.1007/s11426-017-9068-3

Danh, N. T., Teresa, J., \& Bandosz, T. J. (2005). Activated carbons with metal containing bentonite binders as adsorbents of hydrogen sulfide. Carbon, 43(2), 359-367.

https://doi.org/10.1016/j.carbon.2004.09.023

El-Hendawy, A. N. A. (2006). Variation in the FTIR spectra of a biomassunder impregnation, carbonization and oxidation conditions. Journal of Analytical and Applied and Pyrolysis, 75(2), 159-166. https://doi.org/10.1016/j.jaap.2005.05.004

Klein, J., \& Henning, K. D. (1984). Catalytic oxidation of hydrogen sulfide on activated carbons. Fuel, 63(8), 1064-1067. https://doi.org/10.1016/0016-2361(84)90189-3

Latos, M., Karageorgos, P., Kalogerakis, N., \& Lazaridis, M. (2011). Dispersion of odorous gaseous compounds emitted from wastewater treatment plants. Water Air \& Soil Pollution, 215(1-4), 667-677. https://doi.org/10.1007/s11270-010-0508-8

Lee, E. Y., Lee, N. Y., Cho, K. S., \& Ryu, H. W. (2006). Removal of hydrogen sulfide by sulfate-resistant Acidithiobacillus thiooxidans AZ11. Journal of Bioscience \& Bioengineering, 101(4), 309-314. https://doi.org/10.1263/jbb.101.309

Li, H. J., Gu, Y. Y., \& Zhao, Y. C. (2010). Sludge utilization technology. Beijing: Metallurgical industry press.

Li, Y., Shan, S., Yang, R., Gai, X., Mao, J., Huang, N., Tou, Y., \& Meas, A. (2016). Preparation of bamboo biochars by lowtemperature hydrothermal method and its adsorption of organics. Transactions of the Chinese Society of Agricultural Engineering, 32(24), 240-247.

https://doi.org/10.11975/j.issn.1002-6819.2016.24.032

Majid Hayati-Ashtiani. (2012). Characterization of nano-porous bentonite (montmorillonite) particles using FTIR and BETBJH analyses. Particle \& Particle Systems Characterization, 28(3), 71-76. https://doi.org/10.1002/ppsc.201100030

Mcgrath, T. E., Chan, W. G., \& Hajaligol, M. R. (2003). Low temperature mechanism for the formation of polycyclic aromatic hydrocarbons from the pyrolysis of cellulose. Journal of Analytical and Applied Pyrolysis, 66(1-2), 51-70. https://doi.org/10.1016/S0165-2370(02)00105-5

Mohanty, K., Das, D., \& Biswas, M. N. (2006). Preparation and characterization of activated carbons from sterculia alata nutshell by chemical activation with zinc chloride to remove phenol from wastewater. Adsorption, 12(2), 119-132. https://doi.org/110.1007/s10450-006-0374-2

Omar, F., Ubong, E., Jerzy, S., Almoustapha, S., \& Aboubaker, B. (2017). $\mathrm{H}_{2} \mathrm{~S}$ adsorption on $\mathrm{NH}$-decorated graphene: A first principles study. Surface Science, 668, 100-106.

https://doi.org/10.1016/j.susc.2017.10.016

Shang, G., Li, Q., Liu, L., Chen, P., \& Huang, X. (2016). Adsorption of hydrogen sulfide by biochars derived from pyrolysis of different agricultural/forestry wastes. Journal of the Air \& Waste Management Association, 66(1), 8-16. https://doi.org/10.1080/10962247.2015.1094429

Soares, S., Camino, G., \& Levchik, S. (1995). Comparative study of the thermal decomposition of pure cellulose and pulp paper. Polymer Degradation and Stability, 49(2), 275-283. https://doi.org/10.1016/0141-3910(95)87009-1

Titus, S. van Erp, \& Martens, J. A. (2011). A standardization for BET fitting of adsorption isotherms. Microporous and Mesoporous Materials, 145(1), 188-193.

https://doi.org/10.1016/j.micromeso.2011.05.022

Tsai, W. T., Chang, C. Y., \& Lee, S. L. (1998). A low cost adsorbent from agricultural waste corn cob by zinc chloride activa- 
tion. Bioresource Technology, 64(3), 211-217. https://doi.org/10.1016/S0960-8524(97)00168-5

Wu, B., Huang, J. J., \& Zhang, R. J. (2009). Adsorption and catalytic removal of hydrogen sulfide on active carbon (char) at low temperature. Journal of Fuel Chemistry and Technology, 37(3), 355-359.

Xie, L., Yi, Y. F., Hu, X. Y., Zheng, W., \& Chen, Y. (2011). Research progress in desulfurizers. Liaoning Chemical Industry, 40(10), 1084-1087.

Zeng, G. N., Zhou, H. Y., \& Ai, N. (2013). Preparation and optimization of high-performance activated carbons from Sargas- sum Horneri by chemical activation. Acta Scientiae Cricumstantiae, 33(8), 2209-2217.

Zhang, H., Voroney, R. P., Price, G. W., \& White, A. J. (2017). Sulfur-enriched biochar as a potential soil amendment and fertiliser. Soil Research, 55(1), 93-99. https://doi.org/10.1071/SR15256

Zhang, X., Cui, X., Chen, D., Dong, X., \& Tang, J. (2018). Electronic structure and $\mathrm{H}_{2} \mathrm{~S}$ adsorption property of $\mathrm{Pt}_{3}$ cluster decorated $(8,0)$ SWCNT. Applied Surface Science, 428, 82-88. https://doi.org/10.1016/j.apsusc.2017.09.084 